\title{
Study of a gas turbine unit energy efficiency
}

\author{
Alexandr Legkii, Igor Stefanenko, Alexey Kudashev, Vladimir Zlobin, and Natalia \\ Ermilova* \\ Volgograd Technical University, Institute of Architecture and Construction, 400074, Volgograd, \\ Russia
}

\begin{abstract}
The method of the gas turbine unit and the waste heat boiler gas-air duct circuit modernization is considered. The operation scheme of a gas turbine unit and a waste heat boiler with the use of a catalytic afterburner has been shown. There is also a decrease in nitrogen and carbon oxides in the exhaust steam-and-gas mixture due to a deeper cleaning process of the exhaust steam and gas mixture, which leads to an increase in the service life of the waste heat boiler [1]. A more complete process of heat transfer to the coolant in the furnace section of the boiler is performed due to the cleaner steam and gas mixture in the waste heat boiler and due to a decrease in the boiler tubes growth formation by the combustion products. This makes it possible to reduce the cost of fuel consumption by gas burners of the waste heat boiler. Also, as a result of this process, it is possible to reduce fuel consumption for the needs of heating the feed water and the auxiliary needs of a power unit. This article proposes to use lattice devices in the afterburner, treated with active substances by the ion implantation method, as one of the most promising ways of modifying lattice surfaces [2-6]. These processes occurring when the steam-and-gas mixture passes through the afterburner, allow increasing the cycle efficiency factor and limit of maximum allowable concentrations (MAC) emissions for various options for the exhaust steam-and-gas mixture utilization of a gas turbine unit (GTU) and heat supply to the waste heat boiler.
\end{abstract}

\section{Introduction}

Currently the exhaust gases enter the waste heat boiler to heat the feed water and reduce fuel consumption costs to increase efficiency factor at the power facilities where gas turbine units are installed. It is one of the most efficient systems for the electrical and thermal energy generation for today. However, there is an underburned fuel in the form of oxides of carbon and nitrogenous compounds in this steam-and-gas mixture, which leads to a decrease in efficiency factor cycle, as well as an increased content of harmful substances in the exhaust flue gases.

\footnotetext{
* Corresponding author: n.y.ermilova@yandex.ru
} 


\section{Purpose of the study}

This article is devoted to the study of the catalytic afterburner operation on the gas-air flow duct of gas turbines and waste heat boilers [7-9].

\section{Material and research methods}

Classic gas turbine plants operating on flare fuel combustion using gas burners are one of the main sources of harmful substances emissions into the atmosphere. So, when fuel is burned in power plants, a significant amount of harmful substances including nitrogen and carbon oxides is emitted into the atmosphere.

Gas turbine unit GTU -190 with a capacity of 190 MW can be used in the electrical energy production in basic and semi-peak modes. The unit can operate as a part of steamgas blocks, as well as autonomously for the district heating purposes. Fig. 1 shows a diagram of a gas turbine unit GTU -190 with exhaust gas-air duct.

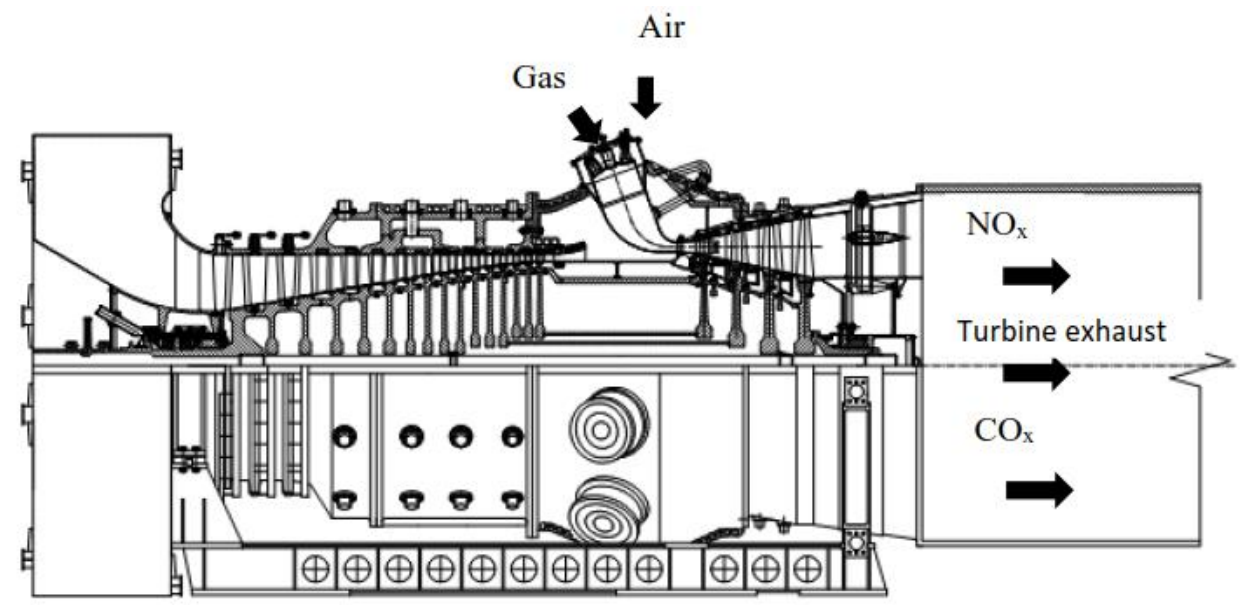

Fig. 1. Gas turbine unit GTU - 190diagram

GTU -190 specifications are shown in Table 1.

Table 1. Part 1

\begin{tabular}{|c|c|}
\hline Specifications & Values \\
\hline Gas temperature in front of the turbine, $\left[{ }^{\circ} \mathrm{C}\right]$ & 1300 \\
\hline Power at ISO generator terminals, $[\mathrm{MW}]$ & 190.0 \\
\hline Power at generator terminals, $[\mathrm{MW}]$ & 185.3 \\
\hline GTU efficiency factor according to ISO, $[\%]$ & 37.0 \\
\hline
\end{tabular}

Table 1. Part 2

\begin{tabular}{|c|c|}
\hline Specifications & Values \\
\hline GTU efficiency factor, $[\%]$ & 36.3 \\
\hline Compressor pressure ratio & 15.8 \\
\hline Air temperature behind the compressor, $\left[{ }^{\circ} \mathrm{C}[\right.$ & 405.0 \\
\hline Fuel consumption, $[\mathrm{kg} / \mathrm{c}]\left(Q_{\mathrm{P}}^{\mathrm{H}}=47313 \mathrm{~kJ} / \mathrm{kg}\right)$ & 10.815 \\
\hline Gas flow behind the turbine, $[\mathrm{kg} / \mathrm{s}]$ & 533.0 \\
\hline Gas temperature behind the turbine, $\left[{ }^{\circ} \mathrm{C}\right]$ & 553.0 \\
\hline Emissions NOx (at $15 \%$ content $\left.\mathrm{O}_{2}\right),[\mathrm{ppm}]$ & 25 \\
\hline GTU power gross, $[\mathrm{MW}]$ & 273.3 \\
\hline
\end{tabular}




\begin{tabular}{|c|c|}
\hline Number of shafts & 1 \\
\hline Number of stages in the turbine & 4 \\
\hline Number of stages in the compressor & 15 \\
\hline Rotational speed, [rev/min] & 3000 \\
\hline Natural gas pressure in front of the block valve (excess), $\left[\mathrm{kgf} / \mathrm{cm}^{2}\right]$ & 25 \\
\hline
\end{tabular}

To increase the gas turbine unit efficiency, it is proposed to install a catalytic afterburner in the exhaust pipe of the turbine, in which the process of ion exchange of the exhaust steam-and-gas mixture and catalytic grids of the afterburner will take place. The proposed method for installing a catalytic afterburner allows increasing the production of the carbon dioxide and nitrogen afterburn substances amount from the combustion products of the resulting gas-air mixture at the outlet of their burners of carbon and nitrogen oxides. The method of ionic materials alloying was used to create doped grids. Catalysts effect is determined by the dehydrogenation reaction of hydrocarbons, which consists in the elimination of hydrogen from the hydrocarbon molecule, which accelerates the combustion process and reduces the concentration of unburned hydrocarbons. This is a method of introducing impurity atoms into the substance surface layer by bombarding its surface with a high-energy ion beam (10-40 KeV) [9]. Installation diagram of a catalytic afterburner in the exhaust outlet GTU -190 is shown in Fig. 2.

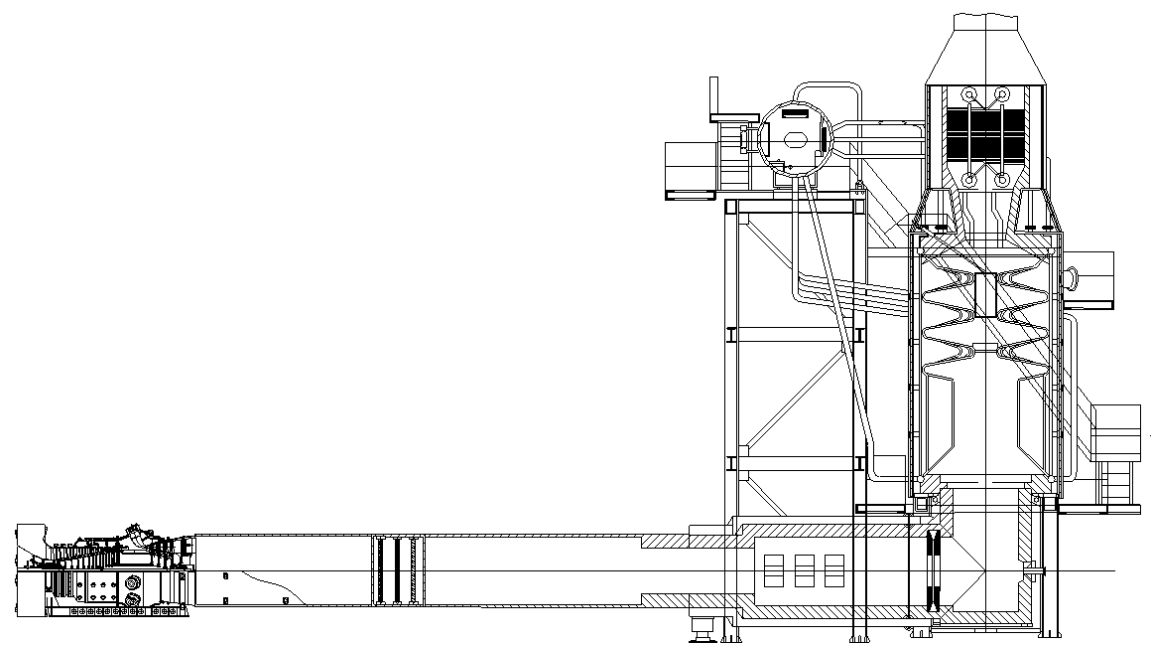

Fig. 2. Installation diagram of a catalytic converter in the exhaust outlet GTU -190

With this type of installation of a catalytic afterburner, the temperature of the exhaust steam-and-gas mixture was calculated, taking into account the passage of gas through the catalytic afterburner. Some of the calculations made are presented in the following formulas [10-15].

Specific work of air compression in the compressor, $\mathrm{kJ} / \mathrm{kg}$,

$$
\begin{gathered}
H_{\mathrm{\kappa}}=\varphi_{\mathrm{a}} c_{c w} T_{\mathrm{B}}\left(\pi_{\mathrm{\kappa} 0}^{\frac{\mathrm{\kappa}-1}{\mathrm{~K}}}-1\right) \eta_{k}^{-1} \\
H_{k}=1.02 \cdot 288\left(9.5^{\frac{1.302-1}{1.302}}-1\right) \cdot 0.865^{-1}=232.97 \mathrm{~kJ} / \mathrm{kg}
\end{gathered}
$$

where $\mathrm{c}_{\mathrm{cw}}=1.02 \mathrm{~kJ} /(\mathrm{kg} \cdot \mathrm{K}), \mathrm{T}_{\mathrm{a}}=288 \mathrm{~K}, \mathrm{k}=1.302$. 
Efficiency factor is determined by the formula

$$
\eta_{k}=\frac{T_{a}\left(\pi_{\mathrm{\kappa}}^{\frac{\mathrm{\kappa}-1}{\mathrm{~K}}}-1\right)}{T_{k}-T_{a}}=\frac{288\left(10^{\frac{1.302-1}{1.302}}-1\right)}{523.061-288}=0.865
$$

Additionally, we will amend the value of the compression work at relative humidity 60 $\% \varphi_{\mathrm{a}}=1.0041$ and $T_{\mathrm{ad}}=288 \mathrm{~K}$.

$$
\begin{gathered}
H_{k}=\varphi_{\mathrm{a} d} c_{c w} T_{f}\left(\pi_{k 0}^{\frac{k-1}{k}}-1\right) \eta_{k}^{-1} \\
H_{k}=1.0041 \cdot 1.01 \cdot 288\left(9.5^{\frac{1.302-1}{1.302}}-1\right) 0.865^{-1}=233.925 \mathrm{~kJ} / \mathrm{kg}
\end{gathered}
$$

Air temperature behind the compressor:

$$
\begin{gathered}
T_{c}=T_{a}+H_{c} / c_{c w} \\
T_{c}=288+\frac{233.925}{1.02}=517.338 \mathrm{~K}
\end{gathered}
$$

Average temperature of the air compression process inside the compressor:

$$
\begin{gathered}
T_{a v}=\left(T_{a}+T_{c}\right) / 2 \\
T_{a v}=\frac{288+517.338}{2}=402.669 \mathrm{~K}
\end{gathered}
$$

or $\mathrm{t}_{\mathrm{av}}=129.669^{\circ} \mathrm{C}$.

The thermophysical properties of air are refined according to the average temperature of the compression process according to the graphs of the true specific heat capacity and the adiabatic index of the combustion products of natural gas (the refined values are assigned with the index «'»):

$$
\begin{aligned}
\grave{c_{\mathrm{pK}}}= & 1.058 \mathrm{~kJ} /(\mathrm{kg} \cdot \mathrm{K}) \\
& \grave{k_{\mathrm{K}}}=1.378
\end{aligned}
$$

The revised value of the specific work of compression of the air engine is found according to the formula (3)

$$
H_{c}=1.058 * 288\left(9.5^{\frac{1.378-1}{1.378}}-1\right) 0.865^{-1}=300.476 \mathrm{~kJ} / \mathrm{kg}
$$

The adjusted value of the air temperature behind the compressor, according to the formula (4)

$$
T_{c}^{`}=288+\frac{307.295}{1.058}=572.004 \mathrm{~K}
$$

The refined value of the compression process average temperature in the compressor is found according to the formula (5)

$$
T_{a v}^{\prime}=\frac{288+572.004}{2}=430.002 \mathrm{~K}
$$


Due to the small (less than $2 \%$ ) change in the average temperature of the air compression process in the compressor, further refinement of the thermophysical parameters of the air is not required.

The coefficient of the combustion products excess air is determined by the formula:

$$
\begin{gathered}
\alpha_{a}=\frac{3000-0,367 T_{\Gamma}}{T_{b}-T_{c}^{\prime}} \\
\alpha_{a}=\frac{3000-0.367 \cdot 1573}{1573-572,004}=2.42
\end{gathered}
$$

Expansion ratio of combustion products in GTU turbines:

$$
\begin{gathered}
\pi_{t \Sigma}=\pi_{c}(1-t r) \\
\pi_{t \Sigma}=9.5(1-0.05)=9.025
\end{gathered}
$$

The specific work of the compressor turbine expansion will be

$$
\begin{gathered}
H_{t 1}=\frac{H_{c}}{v_{1} \eta_{\text {mech }}} \\
H_{t 1}=\frac{300.476}{0.865 \cdot 0.975}=356.278 \mathrm{~kJ} / \mathrm{kg}
\end{gathered}
$$

Combustion gas temperature behind the compressor turbine

$$
\begin{gathered}
T_{\mathrm{T} 1}=T_{\Gamma}-H_{\mathrm{T} 1} / c_{\mathrm{pt} 1} \\
T_{t 1}=1573-356.278 / 1.24=1285.679 \mathrm{~K}
\end{gathered}
$$

Average temperature of the combustion products expansion process in the compressor turbine

$$
\begin{gathered}
T_{a v 1}=\left(T_{b}+T_{t 1}\right) / 2 \\
T_{a v 1}=\frac{1573+1285.679}{2}=1429.339 \mathrm{~K}
\end{gathered}
$$

or $\mathrm{t}_{\mathrm{av} 1}=1156.339^{\circ} \mathrm{C}$.

The thermophysical properties of combustion products are specified at the average temperature of the expansion process and the excess air coefficient $\alpha_{a}=4.0$ :

$$
\begin{gathered}
\grave{c_{e t 1}}=1.17 \mathrm{~kJ} /(\mathrm{kg} \cdot \mathrm{K}) \\
k_{t 1}^{\prime}=1.325
\end{gathered}
$$

The temperature of the combustion products behind the compressor turbine and the average temperature of the expansion process in the compressor turbine are specified:

$$
T_{t 1}^{\prime}=1573-356.278 / 1.17=1268.489 \mathrm{~K}
$$




$$
T_{a v 1}=\frac{1573+1268.489}{2}=1420.744 \mathrm{~K}
$$

Expansion ratio of combustion products in the compressor turbine:

$$
\begin{gathered}
\pi_{t 1}=\left[1-\frac{H_{\mathrm{T} 1}}{c_{e t 1} T_{\mathrm{r}} \eta_{t 1}}\right]^{\frac{k^{\prime}}{1-k}} \\
\pi_{t 1}=\left[1-\frac{356.278}{1.17 \cdot 1573 \cdot 0.865}\right]^{\frac{1,325}{1-1,325}}=2.812
\end{gathered}
$$

Expansion ratio of combustion products in a power turbine

$$
\begin{gathered}
\pi_{t 2}=\pi_{t \Sigma} / \pi_{t 1} \\
\pi_{t 2}=\frac{9.5}{2.812}=3.378
\end{gathered}
$$

The thermophysical properties of combustion products are specified at the average temperature of the expansion process and the excess air coefficient $\alpha_{a}=4.0$ :

$$
\begin{gathered}
c_{e t 2}=1.15 \mathrm{~kJ} /(\mathrm{kg} \cdot \mathrm{K}) \\
k_{t 2}=1.323
\end{gathered}
$$

Specific work of power turbine expansion:

$$
\begin{gathered}
H_{t 2}{ }^{\prime}=c_{e t 2} T_{b 1}\left(1-\pi_{t 2}^{\frac{1-c}{K}}\right) \eta_{t 2} \\
H_{t 2}{ }^{\prime}=1.15 \cdot 1261.579\left(1-3.378^{\frac{1-1,323}{1,323}}\right) \cdot 0.91=339.302 \mathrm{~kJ} / \mathrm{kg}
\end{gathered}
$$

Combustion product temperature behind the power turbine:

$$
\begin{gathered}
T_{t 2}^{\prime}=T_{t 1}-H_{t 2} / c_{e t 2} \\
T_{t 2}^{\prime}=1268.489-\frac{339.302}{1.15}=973.444 \mathrm{~K}
\end{gathered}
$$

Average temperature of the combustion products expansion in a power turbine:

$$
\begin{gathered}
T_{a v 2}=\left(T_{t 1}+T_{t 2}\right) / 2 \\
T_{a v 2}=\frac{1268,489+973,444}{2}=1120,966 \mathrm{~K}
\end{gathered}
$$

or $\mathrm{t}_{\mathrm{av} 1}=847.966^{\circ} \mathrm{C}$.

The thermophysical properties of combustion products are specified at the average temperature of the expansion process and the excess air coefficient $\alpha_{a}=4.0$ :

$$
\begin{aligned}
& \grave{c}_{\text {рт2 }}=1.13 \mathrm{~kJ} /(\mathrm{kg} \cdot \mathrm{K}) \\
& k_{\text {et } 2}=1.317
\end{aligned}
$$

Specific work of power turbine expansion (revised value)

$$
H_{t 2}{ }^{\prime}=c_{e t 2} T_{b 1}\left(1-\pi_{t 2}^{\frac{1-c}{K}}\right) \eta_{t 2}
$$




$$
H_{t 2}{ }^{`}=1.13 \cdot 1279,159\left(1-3.287^{\frac{1-1,317}{1,317}}\right) \cdot 0.91=328.84 \mathrm{~kJ} / \mathrm{kg}
$$

Combustion product temperature downstream of the power turbine (updated value)

$$
\begin{gathered}
T_{t 2}^{\prime}=T_{t 1}-H_{t 2} / c_{e t 2} \\
T_{t 2}^{\prime}=1268.489-\frac{328.84}{1.13}=977.48 \mathrm{~K}
\end{gathered}
$$

\section{Conclusion}

The described study of the catalytic afterburner installation in the exhaust pipe of the outgoing steam-and-gas GTU mixture, will make it possible to better perform the combustion of the turbine fuel, which will lead to the prevention of build-up by underburning products inside the combustion section of the waste heat boiler and its heat pipes. As a result, the content of nitrogen and carbon oxides will decrease, which makes it possible to reduce the total consumption of the gas mixture to the boiler nozzles. This will increase the turbine-boiler cycle efficiency factor and reduce fuel consumption for technological cycles of an energy enterprise.

\section{References}

1. I.Y. Sigal, Nitrogen oxides in combustion products and in the atmospheric air (Chem, Technology, 1985)

2. J.K. Hirvonen, Ion implantation (Published by Academic Press, Hardcover, 1985)

3. I.G. Brown, The Physics and Technology of Ion Sources (John Wiley \& Sons, 2006)

4. V.N. Zlobin, M.G. Bannikov, Hardening of Cutting Tool inserts by Ion Implantation, Proc. Of the 7-th Int. Symp. on Advanced Materials, Islamabad, Pakistan, 470-472 (2001)

5. I.P. Vasiliev, Y. Cherkasov, P.N. Gavrilenko, V.N. Zlobin, Visnyk Shidno ukraïnskogo natsionalnogo universiteta 11(33), (2000)

6. L.R. Kusch, Catalytic coatings to optimize performance burners heat and gas supply systems, Proceedings of the international scientific conference on the 40th anniversary of KSPEU "Energy - 2008: innovations, solutions and perspectives», Heat power industry Kazan 1, 151-154 (2008)

7. V.N. Zlobin, M.G. Bannikov, Employment of an Ion Implantation Technique for Catalyst Coating on Various Substrates, Proc. Of the 7- th Int. Symp. on Advanced Materials, Islamabad. Pakistan, 341-345 (2001)

8. V. N. Zlobin, L.R. Kushch, V.M. Fokin, Gas burner: pat. No. 86282 RU: MPK N 2009105011/22(006667), (2009), Bul. No. 24

9. L.R. Kouchtch, Catalytic coatings to optimize the burners of Heat Systems, Proceedings of the international scientific conference on the 40th anniversary of KSPEU "Energy - 2008: innovations, solutions and perspectives», Kazan, Kazan State. energy. Univ, 151-154, (2008)

10. O.V. Komarov, V.L. Blinov, A.S. Shemyakinsky, Thermal and gas-dynamic calculations of gas turbine plants (Publishing house of the Ural University, Yekaterinburg, 2018) 
11. A.N. Belousov, N.F. Musatkin, V.M. Radko, Theory and calculation of blade machines (Samara Printing House, Samara, 2003)

12. S.V. Tsanev, V.D. Burov, A.S. Zemtsov, A.S. Osyka, edited by S.V. Tsaneva, Gas turbine power plants, manual for universities (MPEI, Moscow, 2011)

13 A.G. Kostyuk, A.N. Sherstyuk, Gas Turbine Installations (Higher School, Moscow, 1979)

14. B.S. Revzin, I. D. Larionov, Gas Turbine Units with Blowers for Gas Transportation, Handbook (Nedra, Moscow, 1991)

15. B.S. Revzin, Axial compressors of gas turbine gas compressor units (USTU-UPI, Yekaterinburg, 2007) 